Published in final edited form as:

J Urol. 2005 June ; 173(6): 1935-1937.

\title{
TESTOSTERONE AS A PREDICTOR OF PATHOLOGICAL STAGE IN CLINICALLY LOCALIZED PROSTATE CANCER
}

\author{
GINGER ISOM-BATZ, FERNANDO J. BIANCO JR., MICHAEL W. KATTAN, JOHN P. \\ MULHALL, HANS LILJA, and JAMES A. EASTHAM ${ }^{\star}$ \\ From the Departments of Urology (GI-B, FJB, MWK, JPM, HL, JAE) and Biostatistics (MWK), \\ Memorial Sloan-Kettering Cancer Center, New York, New York
}

\begin{abstract}
Purpose-Substantial controversy exists in the literature regarding the association between pretreatment testosterone and disease outcome in patients with prostate cancer. We explored the relationship between preoperative total testosterone, and pathological stage and progression in patients with clinically localized prostate cancer treated with radical prostatectomy.
\end{abstract}

Materials and Methods-We retrospectively reviewed the records of consecutive patients with clinically localized prostate cancer treated with radical prostatectomy between January 1990 and June 2003. A total of 326 patients with pretreatment testosterone levels available were eligible for this analysis. Biochemical progression (BCR) was defined by postoperative prostate specific antigen (PSA) greater than $0.4 \mathrm{ng} / \mathrm{ml}$ with a confirmatory increase and it occurred in $41 \mathrm{men}$. No men received adjuvant therapy. Univariate and multivariate logistic regression analyses were done to examine whether pretreatment testosterone was associated with pathological stage. Cox regression was used to assess the association of testosterone and BCR.

Results-Median PSA was $6.01 \mathrm{ng} / \mathrm{ml}$ (range 0.13 to 86), testosterone was $385 \mathrm{ng} / \mathrm{dl}$ (range 133 to 998 ) and followup was 36 months (range 4 to 136). In 245 patients (75\%) disease was organ confined. Lower testosterone correlated with adverse pathological stage on multivariate analysis ( $\mathrm{p}$ $=0.01$ ), as did clinical stage, biopsy grade and PSA. However, we found no relationship between testosterone and BCR after adjusting for covariates. Furthermore, we found no evidence of an interaction between PSA and testosterone $(\mathrm{p}=0.4)$.

Conclusions-On multivariate analysis low preoperative total testosterone was associated with advanced pathological stage but not with BCR. Future studies are warranted with data on more patients who have progressed.

\section{Keywords}

prostate; prostatic neoplasms; prostatectomy; testosterone; disease progression

\begin{abstract}
It has long been acknowledged that androgens are vital to the growth and maintenance of the prostate. ${ }^{1}$ In vitro androgens have caused the proliferation of most human prostate cancer cell lines zthat are well differentiated. In vivo androgens also stimulate the induction and promotion of prostate tumors and prostate tumor xenografts in rodent models, whereas androgen ablation causes tumor regression. 2,3
\end{abstract}

\footnotetext{
*Correspondence: Department of Urology, Sidney Kimmel Center for Prostate and Urological Cancer, Memorial Sloan-Kettering Cancer Center, 1275 York Ave., New York, New York (telephone: 646422-4390; FAX: 212-988-0683; e-mail: easthamj@mskcc.org).

Supported by the American Foundation for Urologic Disease and T32 Training Grant 82088 from the National Institutes of Health (FJB).
} 
There is substantial controversy in the literature regarding the association between pretreatment testosterone and disease outcome in patients with prostate cancer. Numerous epidemiological studies have attempted to determine a relationship between androgens and prostate cancer risk with varied results. A recent study suggested a significant decrease in the risk of prostate cancer with increasing total testosterone. ${ }^{4}$ Other investigators have noted a moderate decrease in risk in men with high levels of serum sex hormone-binding globulin, resulting in lower free, active testosterone. 5,6 Consistently reports associate lower pretreatment testosterone with a significantly poorer treatment response and worse prognosis in metastatic cases. Specifically pretreatment testosterone less than $300 \mathrm{ng} / \mathrm{dl}$ is associated with shorter survival, ${ }^{7}$ suggesting more aggressive disease. ${ }^{8}$ However, this relationship has been more difficult to establish in men with clinically localized prostate cancer.

Currently the established preoperative predictors of pathological stage and prostate specific antigen (PSA) progression are clinical stage, tumor grade and serum PSA. When combined, these factors predict extraprostatic extension with an area under the curve of $0.79 .{ }^{9}$ Finding reliable preoperative markers that allow us to understand the disease more accurately would certainly be useful in disease management. We tested whether serum testosterone improves our ability to predict pathological stage and biochemical recurrence (BCR) in patients with clinically localized prostate cancer treated with radical prostatectomy.

\section{METHODS}

We retrospectively reviewed the clinical records of 3,860 patients diagnosed with clinically localized prostate cancer who were treated with radical prostatectomy between January 1990 and June 2003. Institutional review board approval was obtained and all data were deidentified. Pretreatment testosterone levels were available in 326 patients. Testosterone was determined at individual physician discretion within 4 weeks of any treatment and all tests were analyzed at laboratories at our institution. Of the patients $112(34 \%), 91(28 \%), 79(24 \%)$ and 44 (14\%) underwent operation between 1990 and 1999, in 2000, in 2001 and in 2002 or after, respectively. In 59 of these patients testosterone was determined before the initiation of neoadjuvant hormonal therapy. These patients were included in the analysis because randomized studies have shown no differences in disease recurrence between patients treated or not treated with neoadjuvant hormonal therapy before radical prostatectomy. ${ }^{10}$ Patient data were prospectively collected by physicians and entered by data managers into our prostate cancer Specialized Program in Research Excellence database. The 2002 TNM classification was used to define clinical stage. Histopathological grading was done according to the Gleason grading system and 3 major groups were created for analysis based on the sums Gleason 2 to 6,7 and 8 to 10 . BCR was defined by postoperative PSA greater than 0.2 with a confirmatory increase or the initiation of salvage therapies.

For statistical analyses variables were classified, including Gleason biopsy score as 2 to 6, 7 or 8 to 10 and clinical stage as T1c, T2a, T2b, T2c or T3, while PSA was evaluated in continuous fashion. Frequency distribution of testosterone revealed a median of $375 \mathrm{ng} / \mathrm{ml}$ (range 133 to 998). The 25th and 75th percentiles were 300 and $475 \mathrm{ng} / \mathrm{ml}$, respectively. We analyzed testosterone as continuous and dichotomous with a level of $300 \mathrm{ng} / \mathrm{ml}$ due to the suggested association with poor survival. ${ }^{8}$ Pathological stage was ranked as organ confined disease, focal or established extracapsular extension, invasion into the seminal vesicles or nodal metastasis. Interaction between testosterone and PSA was tested. Univariate and multivariate ordinal logistic regression analysis was done to examine whether pretreatment testosterone was associated with pathological stage, controlling for the common preoperative predictors of PSA, clinical stage, biopsy grade and neoadjuvant hormonal treatment. Cox regression analysis was used to evaluate whether testosterone was associated with biochemical recurrence after 
controlling for the pretreatment predictors listed. In all analyses $\mathrm{p}<0.05$ was considered statistically significant

\section{RESULTS}

Of the 326 patientse valuated 43 had BCR at a median followup of 36 months (range 4 to 133). Median age was 59 years (range 41 to 75), median preoperative PSA was $6.01 \mathrm{ng} / \mathrm{ml}$ (range 0.13 to 86 ) and median testosterone was $385 \mathrm{ng} / \mathrm{dl}$ (range 133 to 998). Table 1 shows preoperative and postoperative patients characteristics. Clinical stage T1c or T2a was present in 220 patients (68\%), while $245(75 \%)$ had organ confined disease. Table 2 lists median testosterone per pathological stage. Testosterone was a predictor of pathological stage on univariate analysis $(p=0.001)$. In a constructed multivariate model that controlled for the other predictors clinical stage, PSA and biopsy Gleason score we found that testosterone treated as a continuous variable emerged as a significant preoperative predictor of pathological stage (OR $95 \%$ CI 1.0 to $1.01, \mathrm{p}=0.01$ ) and, when treated as a dichotomous variable, along with PSA, biopsy grade and clinical stage it also emerged as a significant preoperative predictor of pathological stage (table 3). Higher preoperative testosterone correlated with disease confined to the gland. We also performed the analyses excluding patients who had received any neoadjuvant hormonal therapy. Lower testosterone remained associated with advanced pathological stage in this model (OR for organ confined disease $2.3,95 \%$ CI 1.1 to $5.0, \mathrm{p}=$ $0.03)$.

The figure shows actuarial BCR probabilities depending on testosterone level. On univariate analysis there was no significant association between testosterone and BCR $(\log$ rank $p=0.29)$. Our Cox regression model included PSA ( $10 \mathrm{ng} / \mathrm{ml}$ or greater HR 4.1, $\mathrm{p}=0.01)$, clinical stage (T2 vs T1 HR 4.1, p = 0.02), biopsy Gleason score (8 or greater and 7 vs 6 or less HR 4.9 and 3.2 , respectively, $\mathrm{p}=0.01)$ and testosterone $(\mathrm{p}=0.62)$ as $\mathrm{BCR}$ predictors.

\section{DISCUSSION}

We found a statistically significant association between pretreatment testosterone and pathological stage in patients treated with radical prostatectomy for clinically localized prostate cancer. As testosterone decreased, the likelihood of organ confined disease decreased. This significant association persisted after multivariate analysis despite control for the most widely accepted preoperative predictors.

Similar results were found in a recent study in a large cohort of patients also treated with radical prostatectomy. ${ }^{11}$ Our study validates these results. These 2 studies are the first to show a correlation between total testosterone and pathological stage in clinically localized prostate cancer treated surgically, although this association was made in men with metastatic prostate cancer. Other studies have described the relationship of lower testosterone with more advanced disease. Imamoto et al reported that their patients with localized cancer had higher testosterones than those with D2 disease, ${ }^{12}$ showing more advanced disease with lower androgen. Another study demonstrated that patients with lower testosterone were more likely to have a Gleason score of 8 or higher as well as a higher percent of positive cores on biopsy. ${ }^{13}$ Recently it was reported that men on finasteride, a $5 \alpha$-reductase inhibitor that inhibits the conversion of testosterone to the androgen dihydrotestosterone, had a lower overall rate of cancer but were at increased risk for high grade tumors. ${ }^{14}$ By decreasing intraprostatic testosterone finasteride might have created an environment for high grade cancers that were less dependent on androgens for growth ${ }^{15,16} \mathrm{In}$ another study of interest low serum testosterone in men with newly diagnosed prostate cancer was associated with higher tumor microvessel and androgen receptor density as well as with higher Gleason score. ${ }^{17}$ 
Other investigators have reported results opposite to ours, in which higher testosterone correlated with increased metastatic risk. In a study in men treated with radiation higher testosterone, especially levels greater than $500 \mathrm{ng} / \mathrm{dl}$, correlated with increased metastatic relapse but not with PSA recurrence. ${ }^{18}$ An important difference compared with our study is that the group did not report pathological stage. As a consequence, patients might have had more advanced disease than determined clinically, leading to abnormally high rates of disease progression and recurrence.

There are several hypotheses as to why pathological stage is more advanced in men with lower testosterone. Testosterone might be lower secondary to chronic disease or as a consequence of advanced disease. ${ }^{19}$ Others have suggested that prostate cancer inhibits androgens through negative feedback of inhibin, PSA or dihydrotestosterone. This was recognized as a possible mechanism in a study in which testosterone was found to be higher in patients after the prostate was removed. ${ }^{20}$ Another theory is that with low testosterone the hormonal milieu might be varied enough to disrupt the normal growth and maintenance of prostatic tissue, while the compensatory hyperplasia that results when the prostate atrophies might lead to cell mutations and a consequent selection of androgen independent, aggressive prostate cells. ${ }^{1}$

The limitations of our study include its retrospective nature and diurnal variations in androgen, which were not accounted for in our study. However, all were processed at the same laboratory. The precise reasons that lead to the request for testosterone measurement were unknown. Body mass index and sex-hormone binding globulin, which can affect testosterone levels, were unavailable in our study. Although it is unlikely, a few of these patients might have had a history of hormone replacement therapy but, again, this was unknown.

\section{CONCLUSIONS}

We found that lower testosterone in men with clinically localized prostate cancer treated with radical prostatectomy was associated with a worsening pathological stage. However, whether this correlates with disease recurrence is yet to be seen, possibly due to the small number of recurrences that we observed and the consequent lower statistical power. This information can be useful preoperatively in treatment decisions and surgical planning for the control of prostate cancer.

\section{REFERENCES}

1. Prehn RT. On the prevention and therapy of prostate cancer by androgen administration. Cancer Res 1999;59::4161. [PubMed: 10485446]

2. Lucia MS, Bostwick DG, Bosland M, Cockett AT, Knapp DW, Leav I, et al. Workgroup I: rodent modelsof prostate cancer. Prostate 1998;36::49. [PubMed: 9650916]

3. Bladou F, Vessella RL, Buhler KR, Ellis WJ, True LD, Lange PH. Cell proliferation and apoptosis during prostatic tumor xenograft involution and regrowth after castration. Int J Cancer 1996;67::785. [PubMed: 8824549]

4. Stattin P, Lumme S, Tenkanen L, Alfthan H, Jellum E, Hallmans G, et al. High levels of circulating testosterone are not associated with increased prostate cancer risk: a pooled prospective study. Int J Cancer 2004;108::418. [PubMed: 14648709]

5. Gann PH, Hennekens CH, Ma J, Longcope C, Stampfer MJ. Prospective study of sex hormone levels and risk of prostate cancer. J Natl Cancer Inst 1996;88::1118. [PubMed: 8757191]

6. Dorgan JF, Albanes D, Virtamo J, Heinonen OP, Chandler DW, Galmarini M, et al. Relationships of serum androgens and estrogens to prostate cancer risk: results from a prospective study in Finland. Cancer Epidemiol Biomarkers Prev 1998;7::1069. [PubMed: 9865423]

7. Chodak GW, Vogelzang NJ, Caplan RJ, Soloway M, Smith JA. Independent prognostic factorsin patientswith metastatic (stage D2) prostate cancer. The Zoladex Study Group. JAMA 1991;265::618. 
8. Ribeiro M, Ruff P, Falkson G. Low serum testosterone and a younger age predict for a poor outcome in metastatic prostate cancer. Am J Clin Oncol 1997;20::605. [PubMed: 9391550]

9. Ohori M, Kattan MW, Koh H, Maru N, Slawin KM, Shariat S, et al. Predicting the presence and side of extracapsular extension: a nomogram for staging prostate cancer. J Urol 2004;171::1844. [PubMed: 15076291]

10. Soloway MS, Pareek K, Sharifi R, Wajsman Z, McLeod D, Wood DP Jr. et al. Neoadjuvant androgen ablation before radical prostatectomy in cT2bNxMo prostate cancer: 5-year results. J Urol 2002;167::112. [PubMed: 11743286]

11. Massengill JC, Sun L, Moul JW, Wu H, McLeod DG, Amling C, et al. Pretreatment total testosterone level predicts pathological stage in patients with localized prostate cancer treated with radical prostatectomy. J Urol 2003;169::1670. [PubMed: 12686805]

12. Imamoto T, Suzuki H, Akakura K, Komiya A, Nakamachi H, Ichikawa T, et al. Pretreatment serum level of testosterone as a prognostic factor in Japanese men with hormonally treated stage D2 prostate cancer. Endocr J 2001;48::573. [PubMed: 11789562]

13. Hoffman MA, DeWolf WC, Morgentaler A. Islow serum free testosterone a marker for high grade prostate cancer? J Urol 2000;163::824. [PubMed: 10687985]

14. Thompson IM, Goodman PJ, Tangen CM, Lucia MS, Miller GJ, Ford LG, et al. The influence of finasteride on the development of prostate cancer. N Engl J Med 2003;349::215. [PubMed: 12824459]

15. Scardino PT. The prevention of prostate cancer-the dilemma continues. N Engl J Med 2003;349::297. [PubMed: 12824458]

16. Morgentaler A, Bruning CO 3rd, DeWolf WC. Occult prostate cancer in men with low serum testosterone levels. JAMA 1996;276::1904. [PubMed: 8968017]

17. Schatzl G, Madersbacher S, Haitel A, Gsur A, Preyer M, Haidinger G, et al. Associations of serum testosterone with microvessel density, androgen receptor density and androgen receptor gene polymorphism in prostate cancer. J Urol 2003;169::1312. [PubMed: 12629350]

18. Zagars GK, Pollack A, von Eschenbach AC. Serum testosterone-a determinant of metastatic relapse for irradiated localized prostate cancer. Urology 1997;49::327. [PubMed: 9123693]

19. Iversen P, Rasmussen F, Christensen IJ. Serum testosterone as a prognostic factor in patientswith advanced prostatic carcinoma. Scand J Urol Nephrol Suppl 1994;157::41. [PubMed: 7939452]

20. Miller LR, Partin AW, Chan DW, Bruzek DJ, Dobs AS, Epstein JI, et al. Influence of radical prostatectomy on serum hormone levels. J Urol 1998;160::449. [PubMed: 9679896] 


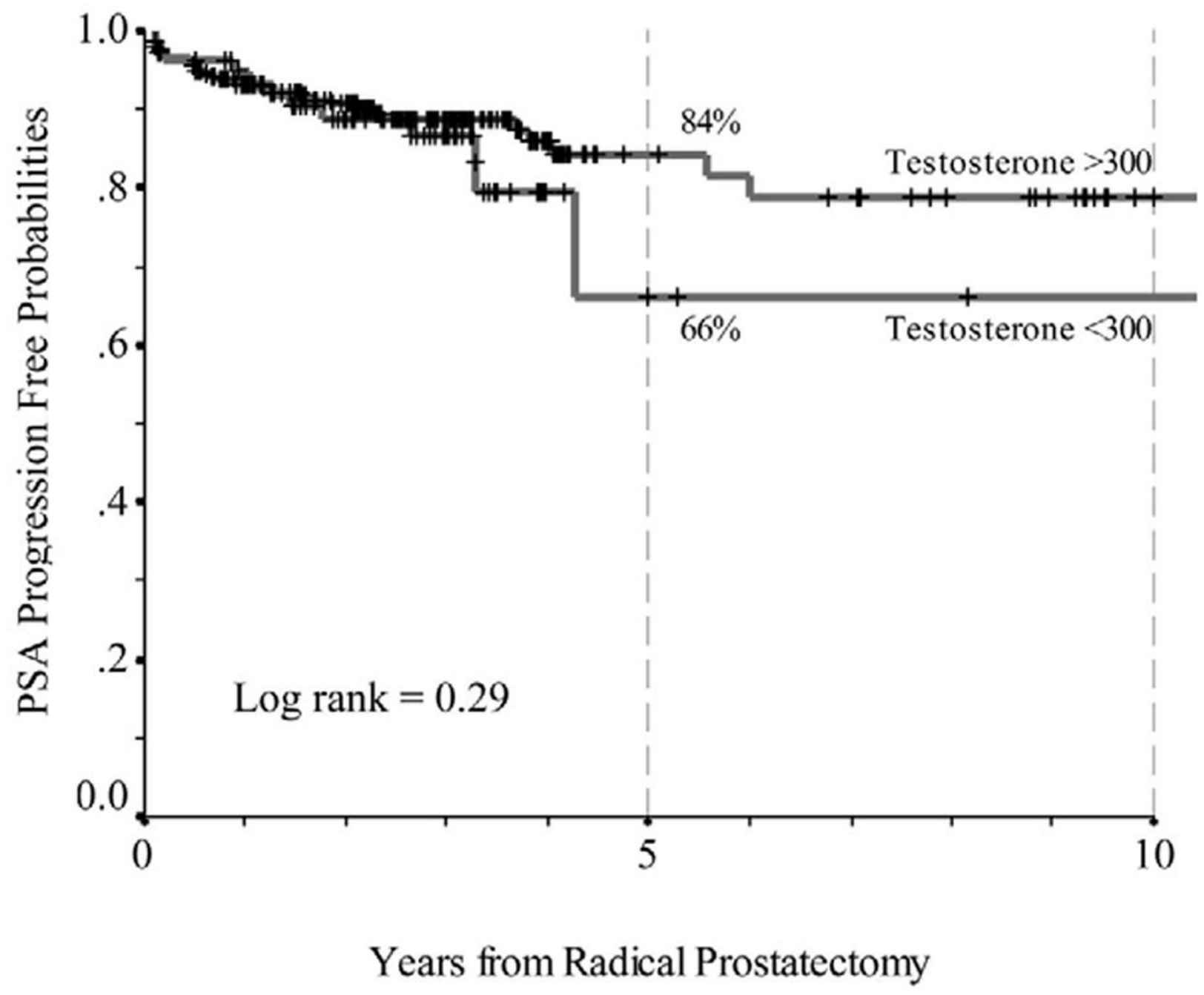

figure.

PSA progression probabilities according to testosterone level 
Table 1

Preoperative And Postoperative Characteristics

No. (\%)

\begin{tabular}{lc}
\hline Clinical stage: & \\
T1c & $150(46)$ \\
T2a & $70(21.5)$ \\
T2b & $43(13.2)$ \\
T2c & $27(8.3)$ \\
T3 & $36(11.4)$ \\
Biopsy Gleason sum: & $179(54.9)$ \\
$4-6$ & $114(34.9)$ \\
7 & $33(10.1)$ \\
$8-10$ & $245(75)$ \\
Pathological stage: & $42(12.8)$ \\
Organ confined & $27(8.3)$ \\
Extraprostatic extension & $12(3.7)$ \\
Seminal vesicle invasion & \\
Pos lymph nodes & \\
\hline
\end{tabular}


TABLE 2

Mean testosterone by pathological stage

Mean Testosterone (range) (ng/dl)

Organ confined

Extraprostatic extension

Seminal vesicle invasion

411 (133-839)

$395(159-998)$

Pos nodes

$365(184-661)$

$318(217-541)$ 
TABLE 3

Logistic regression analysis of preoperative predictors correlating with pathological stage in 326 patients

\begin{tabular}{llr}
\hline \multicolumn{1}{c}{ Risk Factors } & p Value & OR (95\% CI) \\
\hline Testosterone (greater than $300 \mathrm{ng} / \mathrm{ml})$ & 0.01 & $2.40(1.23-4.79)$ \\
Clinical stage (T2 vs T1) & 0.01 & $0.37(0.19-0.74)$ \\
Clinical stage (T3 vs T1) & 0.00 & $0.11(0.04-0.29)$ \\
Biopsy grade (Gleason 7 vs 6 or less) & 0.00 & $0.31(0.17-0.59)$ \\
Biopsy grade (Gleason 8 or greater vs 6 or less) & 0.01 & $0.30(0.11-0.91)$ \\
PSA (greater than 10 ng/ml) & & $0.41(0.22-0.76)$ \\
\hline
\end{tabular}

* Specific correlation with prostate cancer confined to the prostate after radical prostatectomy. 